WellBeing International

WBI Studies Repository

3-1984

\title{
An Attempt to Estimate Teat Quality of Sows by Hand Milking During Farrowing
}

D. Fraser

Agriculture Canada

C. S. Lin

Agriculture Canada

Follow this and additional works at: https://www.wellbeingintlstudiesrepository.org/anatom

Part of the Animal Structures Commons, Animal Studies Commons, and the Veterinary Anatomy Commons

\section{Recommended Citation}

Fraser, D., \& Lin, C. S. (1984). An attempt to estimate teat quality of sows by hand milking during farrowing. Canadian Journal of Animal Science, 64(1), 165-170.

This material is brought to you for free and open access by WellBeing International. It has been accepted for inclusion by an authorized administrator of the WBI Studies Repository. For more information, please contact wbisr-info@wellbeingintl.org.

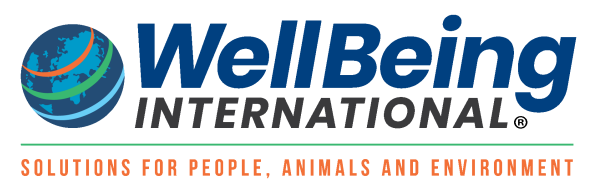




\title{
An Attempt to Estimate Teat Quality of Sows by Hand Milking During Farrowing
}

\author{
D. Fraser ${ }^{1}$ and C.S. Lin $^{2}$
}

${ }^{1}$ Animal Research Centre, Agriculture Canada

${ }^{2}$ Engineering and Statistical Research Institute, Agriculture Canada

\begin{abstract}
KEYWORDS
colostrum, milk, piglet, sow, suckling behavior, teat quality

ABSTRACT

For 21 sows, teats were hand milked individually in a standard way during farrowing in an attempt to produce an index of teat quality. The piglets' teat selection and 14-day weights were then compared with the hand milking results. Of within-litter variation in 14-day weight, $38.67 \%$ was explained by 1 -day weight, and only $4.6 \%$ extra variation by the index derived from hand milking. Use of the index gave no improvement over previous models involving 1-day weight and teat number (anterior to posterior). Hand milking showed a pronounced decline in colostrum yield from the most anterior teat pair $(46.8 \mathrm{~g})$ to the most posterior $(13.7 \mathrm{~g})$; this may help to explain the piglets' strong tendency to select anterior positions. Piglets of high, medium and low 1-day weight differed significantly in liveweight gain, but not in their selection of anterior or posterior teats.
\end{abstract}

Unlike the young of many litter-bearing mammals, a piglet tends to use the one or two teats during most of its suckling period (Donald 1937; McBride 1963). Attachment to specific teats develops in the first hours and days after birth, and does much to eliminate disruptive competition same during suckling (Hartsock and Graves 1916).

Because of this remarkable constancy in teat choice, the quality of individual teats could have an important influence on the weight gains and possibly the survival of piglets. It is common to find large variation in the weaning weights of piglets, with some animals weighing only one-half or one-third as much as their littermates in spite of similar birth weights. Also, much piglet mortality is attributed to the inadequate nourishment of certain animals while the rest of the litter thrives (English and Smith 1975). Variation in the quality of a sow's teats seems a likely explanation for these observations, but has not been studied directly.

Early studies of piglet suckling behavior and growth suggested that the more anterior teats are the most productive, and that piglets compete for the anterior positions, with the larger littermates generally winning their possession (Donald 1931; Barber et al. 1955). Actually, the position of a teat (anterior to posterior) is only a weak indicator of its quality. For example, having an anterior teat confers only a slight 
advantage in forms of milk intake (Hemsworth et al. 1976) and liveweight gain (Fraser and Jones 1975). In most studies, a piglet's birth weight and teat number together account for only about $35-40 \%$ of the variation in body weight at 2-3 wk of age (McBride et al. 1965; Fraser et al. 1979), leaving much of the variation still to be explained.

When a sow is farrowing, colostrum can usually be expressed readily from the teats by hand milking. Preliminary studies showed large variation in the quantity that could be expressed from different teats. We considered that these differences might be related to the productive capacity or to the ease with which milk could be extracted from the teat. Hence, hand milking near the time of farrowing might provide an index to teat quality.

In this study, we carried out hand milking of individual teats on 21 farrowing sows, and then compared the results with the performance of the litters. Our objective was to determine whether the results of hand milking would be closely related to teat selection and the subsequent weight gains of the piglets using the different teats.

\section{MATERIALS AND METHODS}

The experiment involved 21 Yorkshire sows, 13 in their first parity, and 8 in a second or subsequent parity, from the specific-pathogen-free herd of the Animal Research Centre, Ottawa. Sows and litters were used in the experiment whenever it was convenient to attend a farrowing. Three to five days before farrowing was due, sows were moved into farrowing crates in pens 3.2 by $2.5 \mathrm{~m}$. Farrowing was spontaneous in seven cases, and was induced in the remaining 14 cases by an injection of $125-175 \mu \mathrm{g}$ cloprostenol (Estrumate, ICl) after a gestation of 112 or 113 days.

Each farrowing was attended, and the piglets were removed to a warm box before they had a chance to suckle. Hand milking began an average of $1.3 \mathrm{~h}$ after the birth of the first piglet (range of 0-4 h), by which time an average of six piglets (range of 1-12 piglets) had been born but the placenta had not been expelled. An attendant milked each teat for $3 \mathrm{~min}$ in a predetermined. random order. The thumb and one or two fingers were used in a stripping action to express as much milk as possible from the teat during the $3 \mathrm{~min}$. The milk from each teat was collected in a screw-top jar, and was subsequently weighed to the nearest $0.1 \mathrm{~g}$. Milking of all 12 to 16 teats required about $1 \mathrm{~h}$. A few teats were not milked because they were "blind," or showed sign of previous injury. After an additional $1 \mathrm{~h}$ had elapsed (i.e., 2-6 $\mathrm{h}$ after the birth of the first piglet), the milking procedure was repeated, with the teats milked in the same order as before. In this way, each teat was milked for two 3-min periods about $2 \mathrm{~h}$ apart. Piglets were returned to the sow once the milking had been completed.

In conjunction with another study, all litters were adjusted to 8,10 or 12 piglets by fostering during the first day after birth. The desired litter size was determined randomly in advance. Piglets to be removed from experimental litters were selected at random. Piglets to be added were within the existing weight range of the recipient litter, and differed in age by no more than $24 \mathrm{~h}$. An average of 1.7 piglets per litter were added in this way. Piglets with physical abnormalities were culled soon after birth, and all piglets had the "needle" teeth clipped. Piglets were weighed on days 1 and 14 of the lactation. Day 1 weights were taken at 8 to $30 \mathrm{~h}$ of age. Water was available to the piglets from birth, and creep feed from 10 days of age, although very little was eaten until after the experiment ended at day 14. Males were castrated at 10 days of age.

The teats used by the piglets were recorded during 4 days, comprising one of days 3 and 4 after birth, one of days 5 and 6 , one of days 8 to 10 , and one of days 12 to 14. For each suckling episode, the piglets were removed from the sow's pen for $45 \mathrm{~min}$, and were then returned. Ink numbers were marked on the 
piglets' backs for easy identification. The experimenter watched the piglets until suckling began, and then noted, using a tape recorder, the teat used by each piglet during the milk ejection as judged by the behavioral criteria of Whittemore and Fraser (1974). If no suckling occurred in the 15-min period, the piglets were removed for an additional $15 \mathrm{~min}$ and were again returned to the sow. At each suckling episode, the piglets were left with the sow for a total of $15 \mathrm{~min}$. and were then removed for another 45min period. Five consecutive suckling episodes were studied in this way on each of the 4 days for a total of 20 episodes per litter.

\section{Statistical Analysis}

Data on colostrum yield from hand milking were analyzed by the method of least squares with fitting of constants. Factors included in the model were sow, teat number (1 to 6, 7, or 8 , numbered from anterior to posterior), side of the udder (right or left), interaction of side $\times$ teat number, and the order in which the teats were milked. The same model, excluding the order effect, was used to analyze the frequency with which each teat was used. This was defined as the number of suckling episodes in which the teat was occupied by a piglet, out of the 20 episodes observed.

Within-litter regression models for piglet weight at 14 days (14DW) were studied using three independent variables: 1-day weight (1DW), the teat number which was most commonly used by the piglet (TN), and the piglet's milking index (MI). The MI was defined as the colostrum yield (during 6 min of hand milking) of each teat subsequently used by the piglet, weighted according to the number of times the piglet used the teat. That is

$$
M I=\sum_{\mathrm{i}} F_{\mathrm{ij}} C Y_{\mathrm{ij}} / \sum_{\mathrm{i}} F_{\mathrm{ij}}
$$

where $F_{\mathrm{ij}}$ is the frequency with which the piglet suckled the $\mathrm{i}^{\text {th }}$ teat of the $\mathrm{j}^{\text {th }}$ sow, and $C Y_{\mathrm{ij}}$, is the colostrum yield of that teat.

Table 1

Analysis of variance of colostrum yield (hand milking) and the frequency with which each teat was used.

\begin{tabular}{|c|c|c|c|c|}
\hline \multirow[b]{2}{*}{ Source } & \multicolumn{2}{|c|}{ Colostrum yield } & \multicolumn{2}{|c|}{ Frequency } \\
\hline & d.f. & Mean square & d.f. & Mean square \\
\hline Sow & 20 & $2569.5^{\star}$ & 20 & 44.9 \\
\hline Teat number & 7 & $3899.6^{*}$ & 7 & $630.1^{*}$ \\
\hline Side & 1 & 184.8 & 1 & 1.0 \\
\hline Teat number $\times$ side & 7 & 194.6 & 7 & 21.2 \\
\hline Order & 15 & 245.8 & ----- & ----- \\
\hline Residual & 239 & 319.1 & 254 & 33.4 \\
\hline Total & 289 & & 289 & \\
\hline
\end{tabular}

$* P<0.001$.

To investigate how initial weight may affect test selection and subsequent weight gain, six piglets were chosen from each litter based on 1-day weight. These were the two heaviest $(\mathrm{H} 1$ and $\mathrm{H} 2)$, the two lightest (L1 and L2), and the two closest to the median weight (M1 and M2) of each litter. (The suffix, 1 or 2, indicates the heavier and lighter piglet within each pair.) The six piglets were then compared for differences within groups and between groups $(H, M$ and $L)$ by analysis of variance. 


\section{RESULTS}

Hand Milking

Colostrum yield (i.e., total yield during the 6 min of hand milking) showed significant variation attributable to sows and teat number (Table 1). Mean yield from the most anterior teats was about three times greater than from the most posterior ones, with a nearly linear decline from front to rear (Table 2). There were no significant differences between the right and left sides of the udder, no interaction between side and teat number, and no effect of the order in which the teats were milked.

Frequency of Use for Individual Teats

The piglets showed a clear tendency to use the anterior teats more than the posterior ones. Analysis of variance for frequency of use (Table 1) showed that teat number was the only significant factor. Mean frequency declined from front to rear in an almost monotonic manner (Table 2).

\section{Relationship between 14-day Weight and Other Variables}

Within-litter variation in 14-day weight was studied in relation to 1-day weight and either the piglet's milking index (model 1) or the teat number most commonly used by the piglet (model 2) or both (model 3). The regression equations were as follows, with standard errors of the coefficients appearing in parentheses.

Model 1: $14 \mathrm{DW}=0.974+1.845( \pm 0.181) 1 \mathrm{DW}+0.008( \pm 0.002) \mathrm{MI}\left(R^{2}=43.2 \%\right)$

Model 2: $14 \mathrm{DW}=1.584+1.819( \pm 0.181) 1 \mathrm{DW}-0.078( \pm 0.020) \mathrm{TN}\left(R^{2}=43.7 \%\right)$

Model 3: $14 \mathrm{DW}=1.333+1.799( \pm 0.179) 1 \mathrm{DW}-0.056( \pm 0.022) \mathrm{TN}+0.005( \pm 0.002) \mathrm{MI}\left(R^{2}=45.3 \%\right)$

In each model, 1-day weight is the most important variable and accounts for $38.6 \%$ of the total within-litter variation. The milking index and teat number account for an additional 4.6 and 5.0\%, respectively (models 1 and 2). Once both the 1-day weight and teat number had been taken into account, the milking index accounted for only $1.6 \%$ of additional variation.

Table 2.

Mean and standard error of colostrum yield by hand milking and the frequency with which each teat was used, adjusted for differences among sows.

\begin{tabular}{|cccccc|}
\hline & \multicolumn{2}{c}{ Colostrum yield $(\mathbf{g})$} & & \multicolumn{2}{c|}{ Frequency } \\
\cline { 2 - 3 } \cline { 5 - 6 } Test number* & Mean & SE & & Mean & SE \\
\hline 1 & 46.8 & 2.7 & & 19.2 & 0.9 \\
2 & 38.2 & 2.7 & & 15.7 & 0.9 \\
3 & 37.0 & 2.6 & & 16.0 & 0.9 \\
4 & 35.3 & 2.7 & & 16.0 & 0.9 \\
5 & 26.9 & 2.6 & & 11.5 & 0.9 \\
6 & 23.1 & 2.7 & & 9.4 & 0.9 \\
7 & 16.6 & 2.8 & & 8.2 & 0.9 \\
8 & 13.7 & 4.7 & & 5.7 & 1.5 \\
\hline
\end{tabular}

* Teats were numbered from anterior (1) to posterior (6,7, or 8 depending on the sow). 
Analysis of variance on the six piglets selected in each litter showed that differences within the $\mathrm{H}, \mathrm{M}$ and $\mathrm{L}$ groups were small (Table 3). There was a large difference among groups in weight gain, with the piglets of low 1-day weight gaining substantially less than the other two groups (Table 4). The groups did not differ significantly in milking index nor in teat number (Table 3), although there was a tendency for the piglets of low initial weight to have a slightly lower milking index and slightly more posterior teats (Table 4).

\section{DISCUSSION}

Piglets in this study showed a clear tendency to use the anterior teats more than the posterior ones, but littermates of high, medium and low 1-day weight had only slight, nonsignificant differences in their typical positions on the udder. This is similar to most previous findings (e.g. Fraser and Jones 1975), and gives little support to the commonly held view that the piglets of high birth weight tend to appropriate the anterior places (Barber et al. 1955; Scheel et al. 1977).

Table 3.

Analysis of variance for liveweight gain (days 1-14), milking index, and teat number most commonly used, for six selected piglets per litter

\begin{tabular}{|lcccc|}
\hline & & \multicolumn{3}{c|}{ Mean square } \\
\cline { 3 - 5 } Source & d.f. & 14-day gain & Milking index & Teat number \\
\hline Litters & 20 & $1.36^{*}$ & $1568.6^{*}$ & 2.56 \\
Piglets within litters $\dagger$ & 5 & $1.69^{\star}$ & 448.6 & 2.51 \\
H1 vs. H2 & 1 & 0.09 & 173.3 & 5.36 \\
M1 vs. M2 & 1 & 0.08 & 273.6 & 0.38 \\
L1 vs. L2 & 1 & 0.11 & 259.6 & 2.88 \\
Linear among H, M and L & 1 & $7.44^{*}$ & 1319.2 & 2.33 \\
Quadratic among H, M and L & 1 & 0.98 & 406.6 & 1.59 \\
Errorf & 100 & 0.31 & 435.5 & 3.92 \\
\hline
\end{tabular}

†The six selected piglets per litter include the two heaviest $(\mathrm{H})$, two lightest $(\mathrm{L})$ and two closest to the litter's median weight (M) at 1 day of age. The suffix, 1 or 2, indicates the heavier and lighter piglet within each pair.

$\ddagger$ Degrees of freedom for error are 98 and 93 for 14-day gain and hand milking index, respectively.

${ }^{*} P<0.001$.

Table 4.

Mean liveweight gain (days 1-14), milking index, and teat number most commonly used, for six selected piglets per litter

\begin{tabular}{|lccc|}
\hline Piglets* & 14-day gain $(\mathbf{k g})$ & Milking index & Teat number \\
\hline H1 and H2 & 2.62 & 40.1 & 3.41 \\
M1 and M2 & 2.51 & 39.9 & 3.34 \\
L1 and L2 & 2.02 & 32.2 & 3.74 \\
SE of difference & 0.12 & 4.6 & 0.43 \\
\hline * The six selected piglets per litter include the two heaviest (H), two lightest (L), and two closest to the litter's median \\
weight (M) at 1 day of age. The suffix, 1 or 2, indicates the heavier and lighter piglet within each pair. \\
\hline
\end{tabular}

Teat number is statistically significant in the regression models, but accounts for only a small proportion of the variation in 14-day weight. Presumably there were no large differences in milk production between 
anterior and posterior teats during most of the lactation. Similarly, in other studies direct estimation of milk yield has shown only small differences between the front and rear teats (Hartman et al. 1962 Hemsworth et al. 1916). Such small differences in yield are probably not sufficient to explain the piglets' striking tendency to occupy the more anterior teats (Jeppesen 1982).

However, the hand milking data suggest that anterior teats give considerably more colostrum than posterior teats near the time of farrowing. This large but probably short-lived difference might attract piglets to the anterior positions early in the lactation when long-lasting attachments to specific teats are being formed.

Although the milking index was significantly related to 14-day weight, it accounted for relatively little variation, and it did no better than the simple procedure of numbering the teats from front to rear. Presumably the index, with its nearly linear decline from front to rear, functioned as a rough equivalent to teat number in the regression analysis. Indeed, once the effect of teat number had been taken into account, the milking index explained very little additional variation.

As a means of identifying differences among teats that will be related to subsequent piglet growth, the hand milking procedure had important drawbacks. Because of the strong decline from front to rear, hand milking presumably overestimated the quality of anterior teats and underestimated the quality of posterior ones. Furthermore, subsequent work has shown that farrowing sows have sizable ejections of colostrum at irregular intervals (Fraser 1984). For some sows, colostrum ejections appeared to occur during several of the 3-min hand milkings, resulting in anomalously high yields from those teats. These sources of unwanted variation presumably contributed to the relatively weak relationship between the milking index and 14-day weight of the piglets.

A simple procedure to estimate teat quality of sows could be of considerable practical benefit, allowing the producer to select sows for uniform teat quality and to foster piglets according to the number of good quality teats on each sow. This study indicates that hand milking during farrowing, despite its seeming simplicity, does not appear to be a promising technique for comparing teats.

\section{ACKNOWLEDGMENTS}

We are grateful to B. A. Campbell for assistance throughout the study, to S. Foster for assistance in data collection, and to the staff of the A.R.C. pig unit for their helpful cooperation.

\section{REFERENCES}

BARBER, R. S., BRAUDE, R. and MITCHELL, K. G. 1955. Studies on milk production of Large White pigs. J. Agric. Sci., Camb. 46: 97-118.

DONALD, H. P. 1937. Suckling and suckling preference in pigs. Emp. J. Exp. Agric. 5: 361-368.

ENGLISH, P. R. and SMITH, W. J. 1975. Some causes of death in neonatal piglets. Vet. Annu. 15: 95104.

FRASER. D. 1984. Some factors influencing the availability of colostrum to piglets. Anim. Prod. (in press.) 
FRASER, D. and JONES, R. M. 1975. The 'teat order' of suckling pigs. I. Relation to birth weight and subsequent growth. J. Agric. Sci., Camb.84: 387-391

FRASER, D., THOMPSON, B. K., FERGUSON. D. K. and DARROCH, R. L. 1979. The 'teat order' of suckling pigs. 3. Relation to competition within litters. J. Agric. Sci., Camb 92: 257-261.

HARTMAN, D. A., LUDWICK, T. M. and WILSON, R. F. 1962. Certain aspects of lactation performance in sows. J. Anim. Sci. 21: 883-886.

HARTSOCK, T. G. and GRAVES, H. B. 1976. Neonatal behavior and nutrition-related mortality in domestic swine. J. Anim. Sci. 42: 235-241.

HEMSWORTH. P. H., WINFIELD, C. G. and MULLANEY, P. D. 1976. Within-litter variation in the performance of piglets to three weeks of age. Anim. Prod. 22: 351-357

JEPPESEN, L. F. 1982. Teat-order in groups of piglets reared on an artificial sow. I. Formation of teat order and influence of milk yield on teat preference. Appl. Anim. Ethol. S: 335-345.

McBRIDE. G. 1963. The "teat-order" and communication in young pigs. Anim. Behav. 11:53-56.

McBRIDE, G., JAMES, J. W. and WYETH, G. S. F. 1965. Social behaviour of domestic animals. VII. Variation in weaning weight in pigs. Anim. Prod. 7: 67-74.

SCHEEL, D.E., GRAVES, H. B. and SHERRITT, G. W . 1977. Nursing order, social dominance and growth in swine. J. Anim. Sci. 45: 219-229.

WHITTEMORE, C. T. and FRASER, D 1974. The nursing and suckling behaviour of pigs. II. Vocalization of the sow in relation to suckling behaviour and milk ejection. Br. Vet. J. 130: 346-356. 